\title{
ACCOUNTABILITY: A NEW \\ PERFORMANCE IMPROVEMENT PARADIGM
}

\author{
Darlene Van Tiem, CPT
}

WHAT IS THE WORLD coming to? Presidents and politicians are not responsible for wars, deficits, or ethics-not only in the United States but also around the world.

What is the world coming to? Business executives are not responsible for immense corporate losses, missing pension money, or lying to stockholders. Labor is not responsible for expecting more people than necessary to be employed or for the quality of the work.

We are accustomed to sharing--to deflecting-responsibility to the extent that often it appears that no one is responsible. In fact, have we thought about the role or responsibility that training and performance improvement professionals have with respect to the recent business problems at General Motors or Ford Motor Company? General Motors and Ford Motor Company spent plenty on training. Was it effective? Did it add value for organizational as well as external customers?

For a long time we have acknowledged that we often prepared and offered training that we knew was not what was required or that dealt with only part of the total performance problems and opportunities.

We have tools, such as Gilbert's behavior engineering model, that indicated the necessary support was not there to enable training to accomplish the expected returns and results. We have written about it in our professional journals. Experts, such as Brinkerhoff (Brinkerhoff \& Apking, 2001), have warned about the pitfalls of sending employees to training without appropriate prework discussions with management to ensure that the employee clearly knew what was expected and without appropriate follow-up to enable the employee to apply the new skills or knowledge on the job.

We have said that we were doing our best. We require work and the money to survive. How much does it mat- ter if we do not provide the best training possible? We know that about $80 \%$ of training is lost in two months when there is insufficient organizational support. Why, as a profession, do we write about it, talk about it, and not hold ourselves accountable for adding value to all stakeholders?

We even talk about the mega-level (society-level) impact that we should strive toward, aligning everything we use, do, produce, and provide. Then are we part of the problem of the auto industry and other industries that are in trouble? Do we simply do "fix and repair" upon orders, or do we recommend what will be effective and efficient?

\section{AN EXAMPLE IN ANOTHER AREA}

A few weeks ago I had an awakening. I was reading an article about whether ordinary Catholic parishioners should have to pay for the awards being made by the U.S. courts in lawsuits brought by people alleging sexual abuse by priests. The point of the article was that ordinary parishioners are often innocent bystanders. I remembered an incident in my parish many years ago, while I was on the parish council. A very talented organist and choir director left during that time, and there were hushed allegations of sexual encounters, so he was going to another parish. I thought to myself at the time that this was probably not the best solution. But the pastor and others in parish authority had determined that changing parishes was the best way to handle the issue. As a parish council member, should I have notified our bishop (who was known to be liberal)? Was I an innocent bystander when I did nothing? What about parents who might have known? 


\section{COMPARISON}

I wonder now if the fields of training, development, and performance improvement are doing the same thing. Are we acting as innocent bystanders? Are we providing training when there is insufficient organizational support such as coaching, rewards, information, resources, technology, or procedures? Are we designing training when training will not address the real performance problems? Are we training on processes that have to be updated? Are we selecting a training solution before doing a real needs (not wants) assessment that documents the gaps between the current results and consequences and the required ones? We know that unsupported training will not be effective and that the organization will then either ask for more training (because training is politically correct or is the conventional wisdom approach) or ask us to explain why the department receiving the training is not better. And do we know what it will take for the organization to add measurable value to all?

\section{POSSIBLE SOLUTION}

Should we assume partial responsibility for problems in the organizations where we work? And most important, as a profession, do we have to build awareness about our accountability for useful results? Are we professionals (who take responsibility for the consequences of what we do and do not do) or simply technicians (who fix and repair whatever the client asks us to work on)?

It seems to me that sound professional standards have been documented for certification. The International Society for Performance Improvement (ISPI) offers the Certified Performance Technologist (CPT) credential, which involves a rigorous assessment of the performance improvement processes used, requiring descriptions of the projects and signed management-level attestation that the processes used and the results claimed were valid. The certification requires adherence to explicit process standards plus pledging to adhere to the CPT Code of Ethics (see www.ISPI.org, then choose the "Certification" tab). CPT certification provides universally consistent standards for enhancing our accountability and making our positive results repeatable in different situations.

\section{ETHICAL PRIORITIES}

Strengthening our ethical perspective can improve our accountability. Peter Dean, in the October 2006 issue of PerformanceXpress, forcefully discussed the criticality of ethics and the "enemies" of ethical behavior. "Only by being aware of ethical considerations and setting up ethical standards can business leaders [including human performance professionals] help others in their sphere of influence and positively affect their performance and productivity."

Dean cites three ethical enemies that many of us have observed in action in our field:

1. Acting purely in one's own self-interest. Although we all act in our own self-interest, we need to guard against opportunistic behavior. "Consciously combating unethical modes of thinking helps create an atmosphere in which the feelings and rights of all are represented and respected, leading to a more open, healthy, vigorous work environment" (Dean, 2006).

2. Believing in the lack of universal standards. Although CPT standards are widely applicable, sometimes we human performance technology (HPT) professionals adapt our standards to local customs or situational constraints. For example, many clients worry about productivity and insist that training be abbreviated, leaving more production time. They expect that the training will be readily applied without review and application exercises. However, we know that the abbreviated learning will eventually result in client disappointment.

3. Failing to challenge unethical authority. "Research has shown that if a good person is put in an unethical environment, the environment will dominate over the individual. If the organizational system lacks a sense of responsible behavior in its culture or if the individual does not feel free to speak up, then personal decisions on the job will begin to deteriorate into satisfying egoistic needs or taking the easy way out" (Dean, 2006). We need to create a professional environment and sufficient HPT "brand" recognition that our recommendations are welcome.

Clearly, adequate standards and a code of ethics are readily available. Stressing the CPT Code of Ethics, along with the CPT 10 Standards, will enhance our profession. All professionals who have earned the CPT designation have pledged to adhere to the CPT Standards and Code of Ethics. In addition, we need to make the CPT Code of Ethics more prominent to our clients. ISPI's website (ISPI.org) details the CPT Code of Ethics and provides stunning examples of our ethical opportunities. The CPT Code of Ethics is based on the following principles:

1. Add value

2. Validated practice

3. Collaboration 
4. Continuous improvement

5. Integrity

6. Uphold confidentiality

\section{OUR OWN CONTRIBUTION}

\section{TO MEGA}

We have a history of focusing on the individual worker, and more recently we are also focusing on processes and organization. Now, we are gradually evolving our thinking about our responsibility to society, known as mega (Kaufman, 2006), for doing the right thing (not just doing things right). We are improving our practice with our clients and within our partnerships to get the job done right for individual workers, client processes, and client organizations. But are we accountable to ourselves? Have we become passionate about applying the processes we use with clients to our own profession? Do we ensure that what we do and deliver is aligned with adding measurable value for external clients and our society, or do we just restrict ourselves to addressing presenting symptoms?
Do we use HPT or the performance improvement model? Do we assess and then analyze our profession to see if we have an effective vision, mission, goals, and objectives? Do we make sure that we are providing the results that clients require, not just what they think they want (no excuses)? Do we fully understand our own practitioners (workers), our practices (work), our partnerships and interfaces (work environment), and our professional societies (such as ISPI and the American Society for Training \& Development [ASTD]), as well as our shared world?

Do we fully understand why we provide training without sufficient support? Do we assess why so many initiatives do not work?

Do we select, design, and develop the right solutions? Do we collaborate with organizations, such as the Society for Human Resource Management or the American Productivity and Quality Council? Do we use the rigor of Six Sigma? Do we apply the concepts of lean organizations to our own organizations? Do we do real strategic planning, or do we just do tactical or operational planning and call it "strategic"? Are we caught up in politics? Are we too

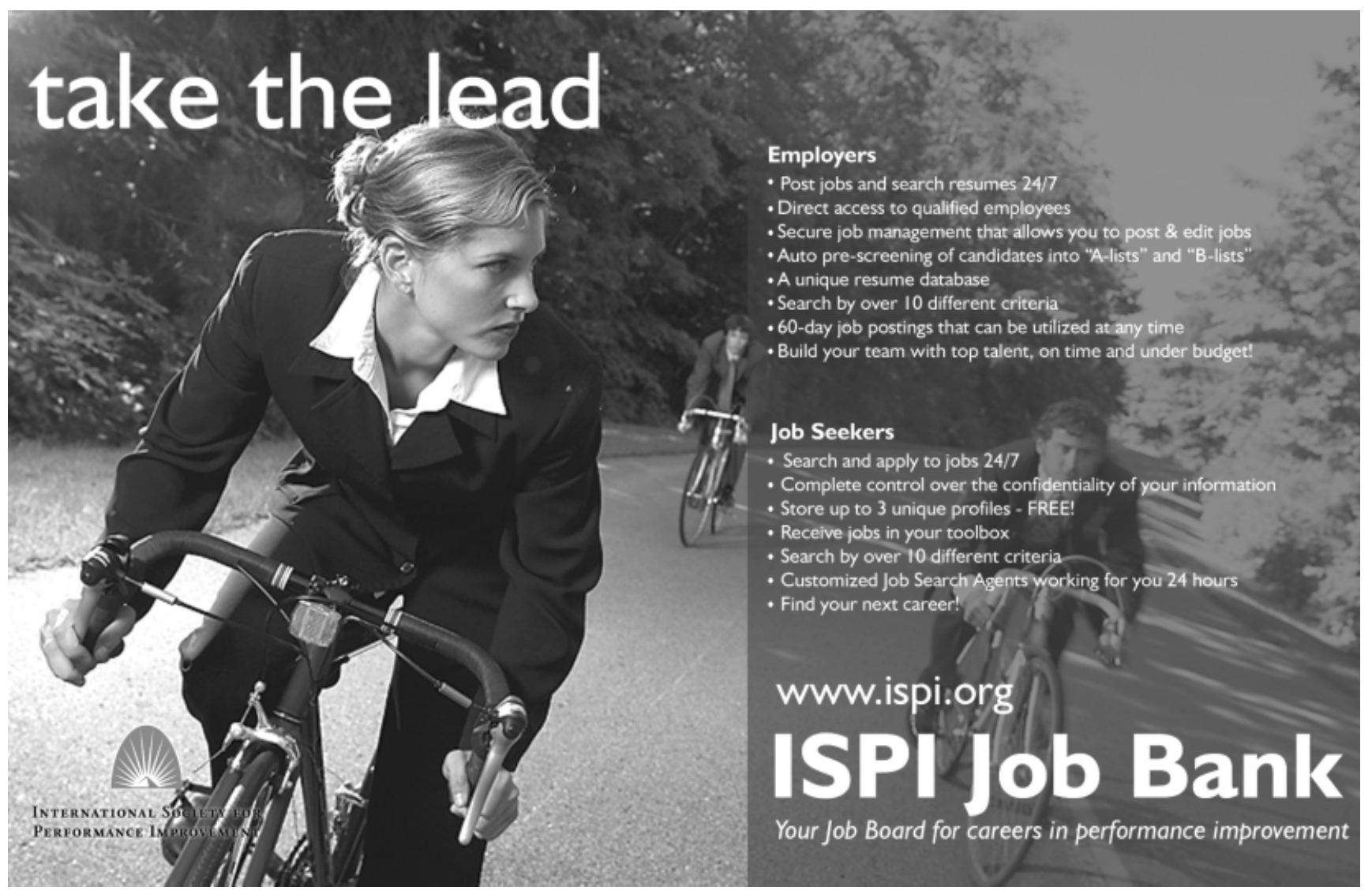


committed to our own notions? Are we playing "victim" to temporarily avoid accountability for results?

Are we accountable for mega-results? Do we focus on our own pet theories and concepts and miss our responsibility to work with human resource development (HRD) and performance improvement professionals to truly make a difference, to improve work opportunities and quality of life, not only within our own countries but also around the world?

In summary, as HPT professionals, we need to continually assess ourselves to ensure that we consistently provide positive results, through systemic, systematic, and collaborative approaches that add clear value.

\section{References}

Brinkerhoff, R.O., \& Apking, A.M. (2001). High impact learning. Cambridge, MA: Perseus.

Dean, P.J. (2006, October). Ethics: An essential tenet of good leadership. PerformanceXpress. Retrieved November 2006 from http://performancexpress.org/0610.
Kaufman, R. (2006). Change, choices, and consequences: A guide to mega thinking and planning. Amherst, MA: HRD Press.

\section{Related Readings}

Binder, C. (2001). Measurement: A few important ideas. Performance Improvement, 40(3), 20-28.

Chevalier, R. (2001). Performance consulting: Job aids for inter-acting with clients. Performance Improvement, 40(1), 28-31.

Kaufman, R. (2006). 30 seconds that can change your life: A decision-making guide for those who refuse to be mediocre. Amherst, MA: HRD Press.

Rossett, A. (1999). Understanding people in organizations who aren't us. Performance Improvement, 38(1), 16-19.

Van Tiem, D.M., Moseley, J.L., \& Dessinger, J.C. (2004). Fundamentals of performance technology (2nd ed.). Silver Spring, MD: International Society for Performance Improvement.

DARLENE VAN TIEM, CPT, PhD, CPLP, is associate professor emeritus and coordinator in the Performance Improvement and Instructional Design graduate program, University of MichiganDearborn. In addition, Darlene is on the adjunct faculty of the Boise State University Instructional \& Performance Technology graduate program. Darlene was human resource director at AT\&T Yellow Pages for Michigan, Ohio, Indiana, and Wisconsin and curriculum manager for General Motors Technical Training (North America) including GM suppliers. The lead author of two best-selling, award-winning ISPI books: Fundamentals of Performance Technology (2nd ed., 2004) and Performance Improvement Interventions (2001), Darlene serves on ISPI's board of directors, has been recognized by ASTD as National Technical Trainer of the Year (1992), and has received the ASTD National Excellence in Leadership Award (1993). She has presented at many international and state conferences and chapter meetings for ISPI, ASTD, Academy of Human Resource Development (AHRD), American Association for Adult and Continuing Education (AAACE), HRA, and National Association for Developmental Education (NADE). Darlene may be reached at dvi@umd.umich.edu. 